\title{
Identification of cheese mite species inoculated on Mimolette and Milbenkase cheese through cryogenic scanning electron microscopy
}

\author{
J. P. Melnyk, ${ }^{* 1}$ A. Smith, ${ }^{*}$ C. Scott-Dupree, $†$ M. F. Marcone, ${ }^{*}$ and A. Hill* \\ *Department of Food Science and \\ †School of Environmental Sciences, University of Guelph, Guelph, Ontario, Canada, N1G 2W1
}

\begin{abstract}
Samples of Mimolette (France) and Milbenkase (Germany) cheeses traditionally ripened by mites were analyzed to determine the mite species present on each sample. Scientific literature was reviewed to understand which mite species most commonly infest cheese. Morphological features possessed by mites were then studied to understand what unique characteristics are required to ensure accurate identification. After identification and compilation of a detailed key of stored food mites (subclass Acari, order Astigmata) and their delineating features, the mites were viewed through a cryogenic scanning electron microscope. It was determined that Mimolette cheese is inoculated with Acarus siro L. The features studied to identify this mite species included idiosomal length and shape, setae length and arrangement, leg size, placement of anus and genitals, and solenidia shape. The Milbenkase cheese is inoculated with Tyrolichus casei Oudemans, which was evident after viewing the same features used to identify $A$. siro and the supracoxal seta shape. With this knowledge, further research can be conducted on the 2 cheese varieties to understand what chemical, physical, and microbial changes occur within the cheeses because of mites. It is important to identify the mite species present on each cheese variety to improve our understanding of their role in creating the distinctive characteristics that set these cheeses apart from others.
\end{abstract}

Key words: cryogenic scanning electron microscopy, Mimolette, Milbenkase, cheese mite species

\section{INTRODUCTION}

The use of mites to ripen cheese is an ancient tradition practiced most commonly in France and Germany. Other than the introduction of new flavors, nothing is known about the chemical, physical, and microbial changes that occur within the cheese caused by the

\footnotetext{
Received November 23, 2009.

Accepted May 1, 2010.

${ }^{1}$ Corresponding author: jmelnyk@uoguelph.ca
}

addition of mites. When cheese is ripened with mites, a nutty, fruity flavor and aroma develops. Although no studies have determined how mites induce these flavor changes, it is believed through sensory observations that the mites are responsible for this flavor development. The mites of interest are used to produce Mimolette cheese in and around Lille, France and to produce Milbenkase in Wurchwitz, Germany. No previous research has been published on these 2 cheese varieties or the effect of mites on the ripening process of cheese. However, before conducting these studies, it was important to identify which mite species are used to inoculate the cheeses. Hughes (1976) and Krantz (1978) identified mite species that commonly inhabit cheese and provided detailed information on the morphological features used to identify them. Species include $A c$ arus siro, Acarus farris, Acarus immobilis, Tyrophagus putrescentiae, Tyrophagus longior, Tyrophagus neiswanderi, Tyrophagus palmarum, and Tyrolichus casei. The species of interest are known as stored food mites from subclass Acari, order Astigmata.

Many of the above-mentioned species are common pests and infest stored cheese in North America and Europe (Hughes, 1976). They grow in conditions greater than $4^{\circ} \mathrm{C}$ and $60 \%$ relative humidity, which are common storage conditions for cheese ripening, which makes infestation prevention difficult (Peace, 1983). Although the cheese varieties that are the focus of this study are purposely inoculated with mites, understanding the species will benefit all areas of the North American and European cheese industry, including producers of these specialty cheeses or those with infestation problems.

The defining morphological features of the mites were researched to understand their anatomy as well as sizing, placement, and proper nomenclature of the specific features. It is important to understand which physical features are used to distinguish between mite species before cryogenic scanning electron microscopy (cryo-SEM) because identification can be made using only a few unique features that set one species apart from the others.

Cryogenic SEM is an effective tool for viewing mites because the high resolution makes it suitable for view- 
Table 1. Comparison of features used to distinguish between Acarus siro and Tyrolichus casei

\begin{tabular}{|c|c|c|}
\hline Defining feature & Acarus siro & Tyrolichus casei \\
\hline Idiosoma length & 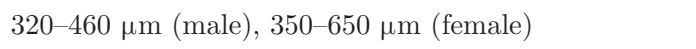 & 450-550 $\mu \mathrm{m}$ (male), 500-700 $\mu \mathrm{m}$ (female) \\
\hline Idiosoma shape & Slender body, rounded posterior & Round body \\
\hline Idiosoma setae & $\begin{array}{l}\text { Most are short. Scapular setae are } 25 \% \text { idiosoma } \\
\text { length; internal scapular setae are slightly longer than } \\
\text { external scapular setae; dorsal setae } 1-4 \text { are short; } \\
\text { exterior humeral, interior humeral, anterior lateral, } \\
\text { and posterior lateral setae are all short, exterior } \\
\text { humeral being the longest; interior vertical setae } \\
\text { is four times longer than exterior vertical setae. }\end{array}$ & $\begin{array}{l}\text { Most are long. Dorsal setae } 1 \text { is short, dorsal setae } 2-4 \text { are } \\
\text { long; dorsal setae } 2 \text { is } 2-3 \text { times longer than dorsal setae } 1 \text {; } \\
\text { anterior lateral setae is } 4-6 \text { times longer than dorsal setae } 1 \text {. }\end{array}$ \\
\hline Posterior setae & $\begin{array}{l}\text { Two short pairs: external sacral setae, } \\
\text { postanal setae } 3 \text {. Two long pairs: internal } \\
\text { sacral setae, postanal setae } 2 \text {. }\end{array}$ & $\begin{array}{l}\text { Eight long pairs: dorsal setae } 3-4 \text {, posterior } \\
\text { lateral setae, internal scapular setae, external } \\
\text { scapular setae, postanal setae } 1-3\end{array}$ \\
\hline Leg size & Enlarged genu and femur & Small, narrow legs \\
\hline Solenidia & $\begin{array}{l}\text { Projection angle }<45^{\circ} \text {, thick base, narrows in } \\
\text { middle, terminates with egg-shaped tip }\end{array}$ & $\begin{array}{l}\text { Projection angle approximately } 45^{\circ} \text {, } \\
\text { cylindrical, slight expansion in middle }\end{array}$ \\
\hline Anus/genitals & Anus lies between fourth pair of legs & Not investigated \\
\hline Supracoxal setae & Not investigated & $\begin{array}{l}\text { Extended point, expanded base, and } \\
\text { distinctive lateral projections }\end{array}$ \\
\hline
\end{tabular}

ing small biological samples such as mites. Scanning electron microscopy allows for clear images of small details that cannot be viewed using traditional microscopy techniques such as light microscopy (Sargent, 1986). Cryogenic SEM has the ability to dehydrate and preserve a sample's original shape. Because the cuticle layer enclosing a mite is delicate, it is susceptible to deformation and complete collapse. By cryogenically preparing the mite, dehydrating the mites while maintaining their original structure is made possible.

It was hypothesized that the mite species infesting the Mimolette and Milbenkase cheese samples would be from the group of stored food mites identified by Hughes (1976) and Krantz (1978) and that viewing the unique morphological features through cryo-SEM would allow for accurate identification of the mite species. Successful identification is important to further research the effects that each species has on the cheese it inhabits.

\section{MATERIALS AND METHODS}

Samples of Mimolette and Milbenkase cheese containing live mites were obtained from France and Germany, respectively. The cheese was stored in an incubator at $10^{\circ} \mathrm{C}$ and $80 \%$ relative humidity for the duration of the study. A sample of Mimolette cheese mites was transferred to a local Parmesan cheese to facilitate further growth.
Mites were viewed using cryo-SEM (S-570, Hitachi, Tokyo, Japan) using a variety of methods and mounting techniques.

1. Samples were viewed by cutting and mounting a small piece of cheese containing mites onto copper holders for the cryopreparation system (Emitech K1250X, Ashford, UK) using TissueTek OCT (Sakura Finetek USA Inc., Torrance, CA).

2. Samples were prepared by individually selecting and placing mites onto a copper mount using Tissue-Tek OCT.

The preparation of samples for cryo-SEM followed that described by Ochoa et al. (2005) and Kumar et al. (2001) with some modifications. Mite samples were quickly submerged into liquid nitrogen slush at $-196^{\circ} \mathrm{C}$ for freezing. The samples were then transferred to the cryogenic preparation system under vacuum, where surface ice was sublimated at $-80^{\circ} \mathrm{C}$ for $60 \mathrm{~min}$. Once the ice was removed, samples were sputter coated with $30 \mathrm{~nm}$ of gold at $-160^{\circ} \mathrm{C}$ to make them more conductive to electrons. The samples were then transferred under vacuum to the cold stage of the SEM and held at a temperature of $-140^{\circ} \mathrm{C}$. Samples were viewed at an accelerating voltage of $10 \mathrm{kV}$. Photographs were recorded using imaging software (Quartz PCI, Vancouver, British Columbia, Canada). 

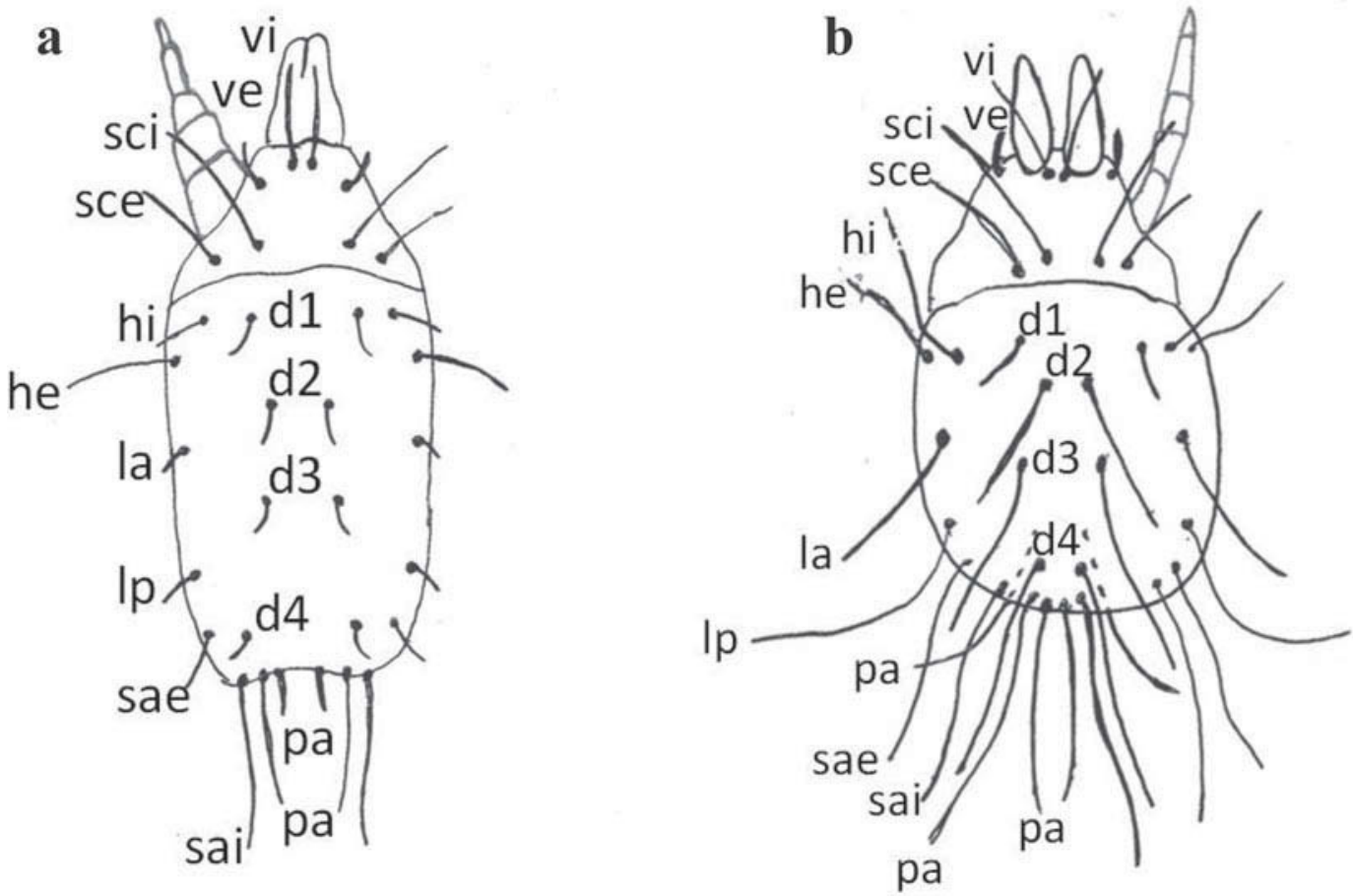

Figure 1. Sketch of Acarus siro and Tyrolichus casei highlighting major differences between the 2 species. a) Acarus siro female dorsal view highlighting slender idiosoma shape and long length, large leg size, and setae of the idiosoma: internal and external vertical (vi and ve, respectively), internal and external scapular (sci and sce, respectively), internal and external humeral (hi and he, respectively), anterior and posterior lateral (la and lp, respectively), dorsal 1 to 4 ( $\mathrm{d} 1, \mathrm{~d} 2, \mathrm{~d} 3, \mathrm{~d} 4)$, internal and external sacral (sai and sae, respectively), and postanals (pa). b) Tyrolichus casei male dorsal view highlighting shorter, rounder idiosoma, smaller leg size, and longer setae of the idiosoma (diagrams adapted from Hughes, 1976).

$\mathbf{a}$
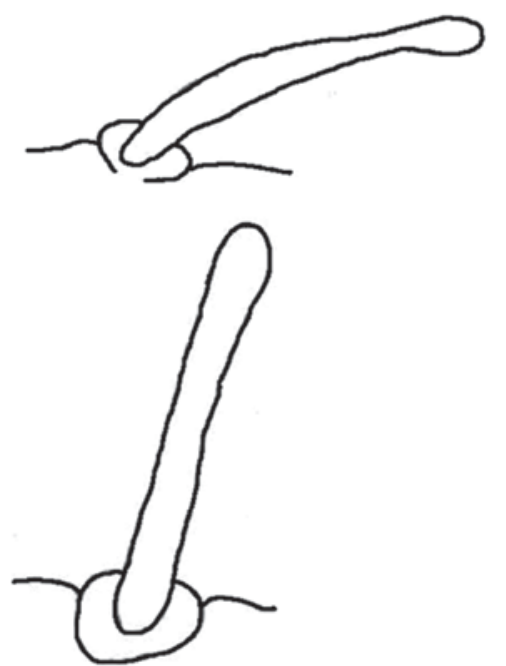

b

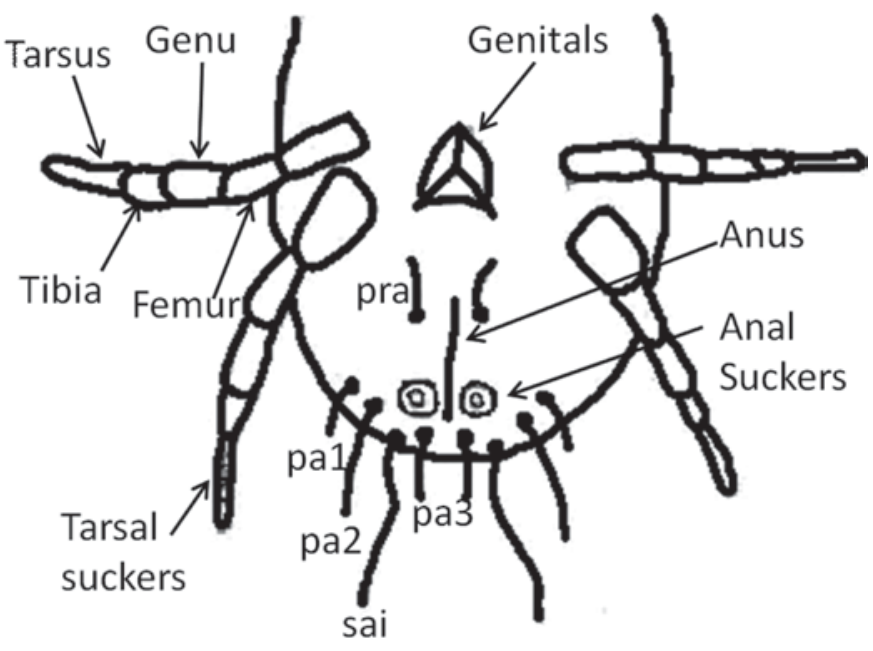

Figure 2. a) Acarus siro (above) and Acarus farris (below) lateral view of solenidia highlighting the differences in shape and projection angle from the tarsus of leg 1 (diagram adapted from Gorham, 1987). b) Acarus siro male ventral view highlighting position of leg segments, genitals, anus, anal suckers, tarsal suckers, and setae of the anus: 3 postanals (pa1, pa2, and pa3) and preanals (pra). sai = internal sacral setae (diagram adapted from Hughes, 1976). 

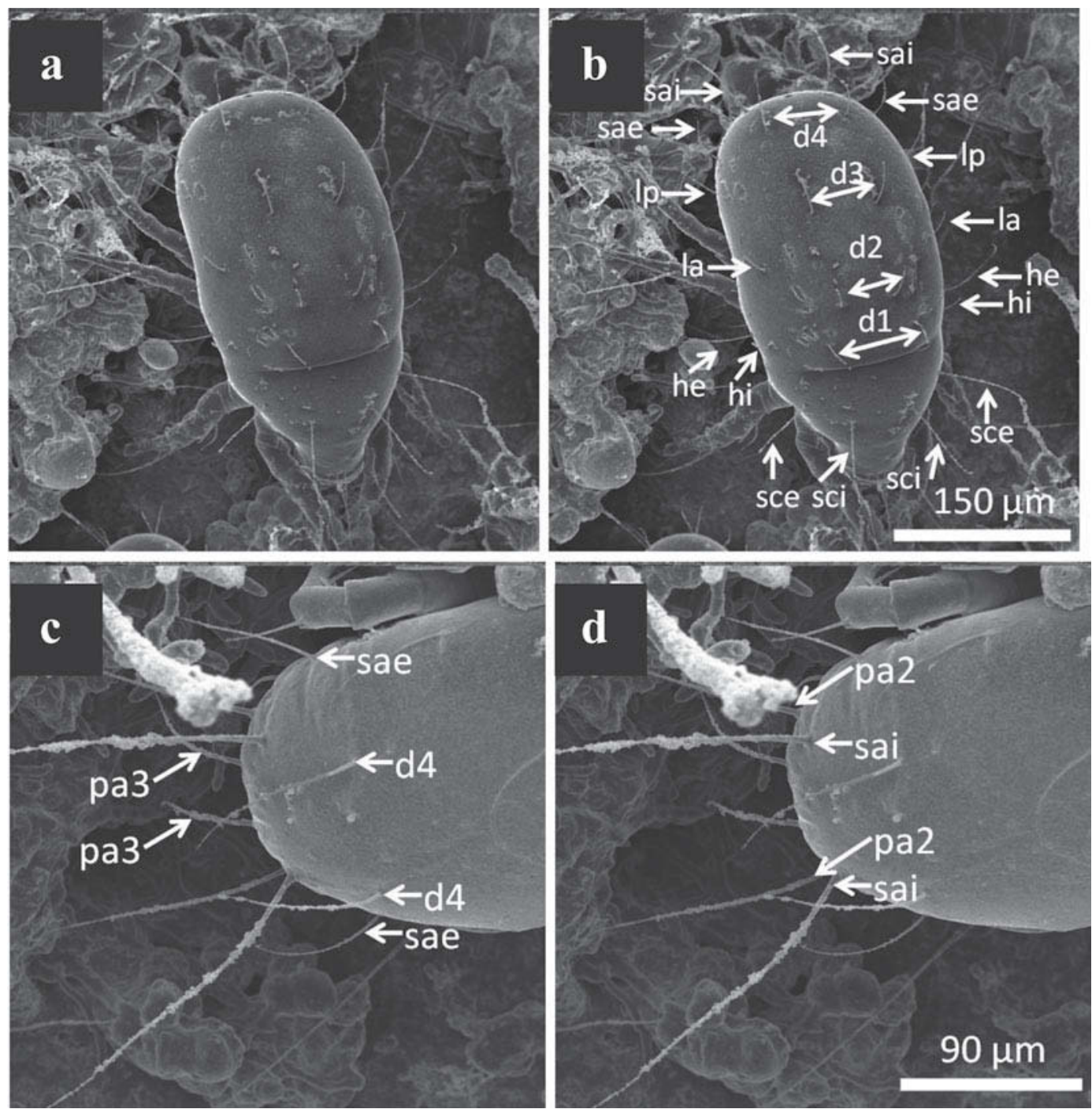

Figure 3. Cryogenic scanning electron microscopy images of Acarus siro. a) Dorsal view highlighting length and shape of the idiosoma. b) Dorsal view highlighting the placement of all idiosomal setae. c) Dorsal view of posterior highlighting the placement of the 2 short pairs of posterior setae. d) Dorsal view of posterior highlighting the placement of the 2 long pairs of posterior setae. Idiosomal setae: internal and external scapular (sci and sce, respectively), internal and external humeral (hi and he, respectively), anterior and posterior lateral (la and lp, respectively), dorsal 1 to 4 (d1, d2, d3, d4), internal and external sacral (sai and sae, respectively), and postanals (pa2, pa3, pa4).

\section{RESULTS AND DISCUSSION}

After reviewing the literature, it became evident that only a few select morphological features could be used to distinguish between mite species (Table 1). The features of greatest importance included idiosoma length (Figure 1a and 1b), body and leg color, shape of the body and legs (Figure 1a and 1b), setae of the idiosoma (Figure 1a and 1b), solenidia shape (Figure 2a), genital shape and placement, and anus, including setae arrangement around the genitals and anus (Figure $2 \mathrm{~b}$ ).

After viewing the mites infesting the Mimolette cheese, it was evident that the species was A. siro L. Acarus siro has an idiosoma length of 320 to $460 \mu \mathrm{m}$ for males and 350 to $650 \mu \mathrm{m}$ for females as reported by Hughes (1976). Figure 3a shows an A. siro male, originally from France, on a piece of Parmesan cheese. This particular mite has an idiosomal length of approximately $340 \mu \mathrm{m}$ with a slender body and rounded posterior that is characteristic of $A$. siro (Hughes, 1976).

Figure $3 \mathrm{~b}$ is a dorsal view of $A$. siro with labels highlighting the idiosomal setae that are of importance when identifying this species. The scapular setae (sc) are arranged in a transverse row across the idiosoma and are approximately $25 \%$ of the idiosomal length (Hughes, 1976). The internal scapular setae (sci) are slightly longer than the external scapular setae (sce), which agrees with the species' patterns described by Hughes (1976). 

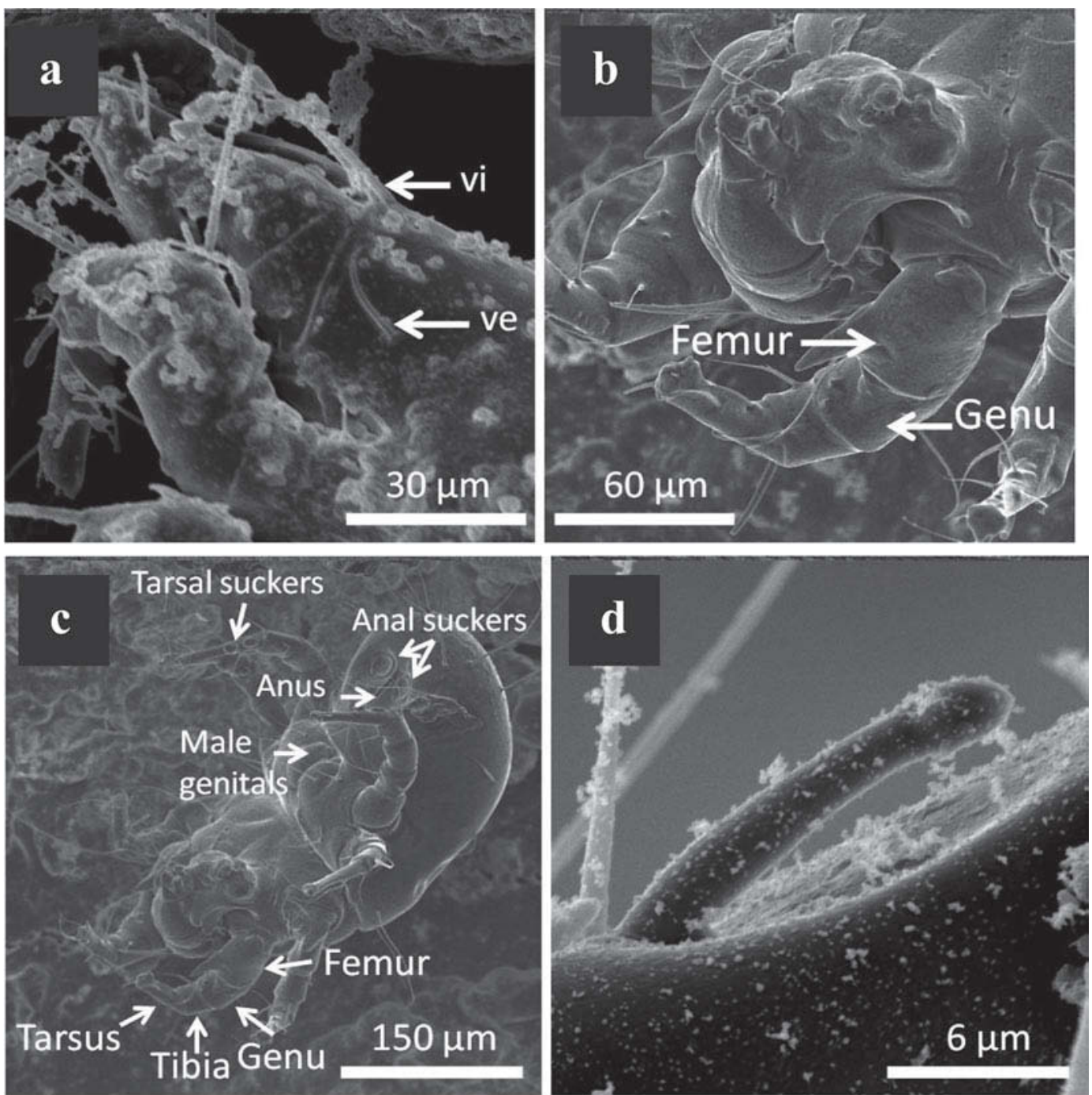

Figure 4. Cryogenic scanning electron microscopy images of Acarus siro. a) Lateral view of anterior highlighting the placement and length of the vertical interior and exterior setae (vi and ve, respectively). b) Ventral-lateral view highlighting the enlarged femur and genu. c) Male ventral view highlighting the 4 segments of the leg and the placement of the genitals, anus, anal suckers, and tarsal suckers. d) Male lateral view of solenidia located on tarsus 1 of the left leg highlighting its unique shape and projection angle of less than $45^{\circ}$.

The dorsal setae (d1-d4) are short, rarely extending past the base of the setae, which is directly posterior, and are all arranged in a straight line from anterior to posterior (Hughes, 1976). The interior humeral (hi), exterior humeral (he), anterior lateral (la), and posterior lateral (lp) setae are all short, with the exterior humeral setae being the longest (Hughes, 1976). Figures 3c and 3d show the posterior of $A$. siro and clearly depict the arrangement of all posterior setae. Characteristic of $A$. siro are 4 pairs of posterior setae; 2 pairs are short and 2 pairs are long (Hughes, 1976). Figure 3c highlights the external sacral setae (sae) and postanal setae 3 (pa3), which are 2 short pairs. Figure 3d highlights the internal sacral setae (sai) and the postanal setae 2 (pa2), which are 2 long pairs. The setae arrangement agrees with information reported by Hughes (1976). The last set of idiosomal setae are the interior and exterior vertical setae (vi and ve, respectively), as shown in Figure 4a. They are located at the anterior end of the body on the propodosoma and extend almost to the tip of the chelicerae, with the interior vertical setae being approximately 4 times longer than the exterior vertical setae (Hughes, 1976).

Figure 4b displays leg 1, highlighting the genu and femur, the first 2 segments of the leg. The enlarged size compared with the other 3 legs is unique to $A$. siro (Hughes 1976).

Figure $4 \mathrm{c}$ is a ventral view of a male $A$. siro highlighting the genitals, anus, anal suckers, and tarsal suckers. The male genitals of $A$. siro lie between the coxae of 

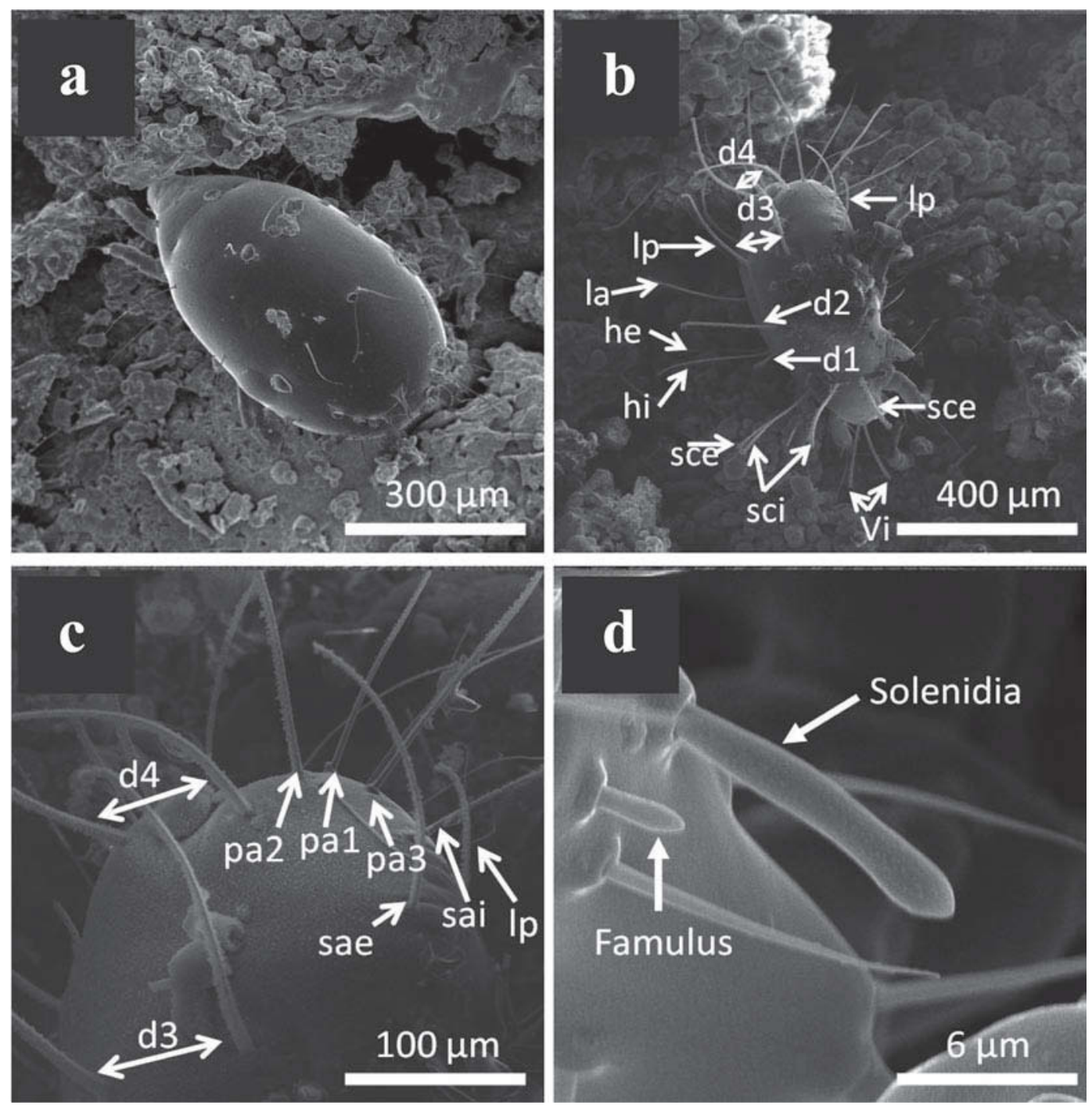

Figure 5. Cryogenic scanning electron microscopy images of Tyrolichus casei. a) Dorsal view highlighting the length and shape of the idiosoma. b) Dorsal-lateral view highlighting the placement of all idiosomal setae. c) Dorsal view of posterior highlighting the placement of the 8 pairs of long setae that project outward forming a fan-like train. d) Lateral view of solenidia located on tarsus 1 of the right leg highlighting its unique shape and projection angle of approximately $45^{\circ}$. Setae: internal and external scapular (sci and sce, respectively), internal and external humeral (hi and he, respectively), anterior and posterior lateral (la and lp, respectively), dorsal 1 to 4 (d1, d2, d3, d4), internal and external sacral (sai and sae, respectively), and postanals (pa1, pa2, pa3).

the fourth pair of legs (Hughes, 1976). This species has anal suckers at each side of the anus that lie toward the posterior of the anal opening (Hughes, 1976). Suckers are also present on the tarsus of leg 4, arising closer to the proximal end (Hughes, 1976).

Another important feature used to distinguish between mite species is the solenidia, which are projections arising from the tarsus of legs 1 and 2. Figure $4 \mathrm{~d}$ is the solenidion from tarsus 1 of the left leg. The picture shows a projection angle of less than $45^{\circ}$ from the tarsus, which is characteristic of A. siro (Hughes, 1976). The shape of the solenidia is thick at the base and narrow in the middle, terminating with an eggshaped tip (Hughes, 1976).

Previous work by Solomon (1962) stated that A. siro is very common in Britain and other temperate regions in Europe such as France. This mite is known to infest cheese and mold and produces a brown dust on the foodstuff it is infesting (Solomon, 1962). Our assessment of morphological features and ecology agree with these findings, strengthening the evidence that $A$. siro is the mite species infesting the Mimolette cheese.

After viewing the mite samples on the Milbenkase cheese, it was evident that the species of mite differed 


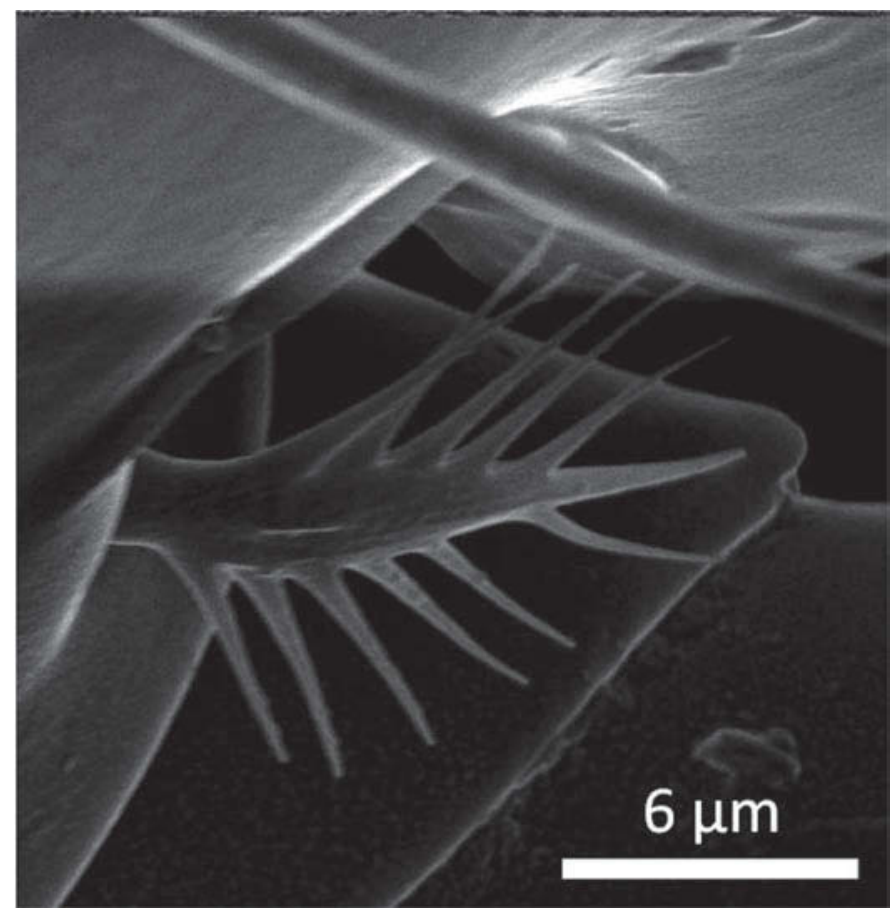

Figure 6. Tyrolichus casei lateral view of the supracoxal seta highlighting the shape, which consists of an extended point, expanded base, and lateral projections.

from that on the Mimolette. The body was rounder than that of $A$. siro and the idiosomal setae were longer. Based on descriptions by Hughes (1976) and Krantz (1978), it was concluded that the species was T. casei Oudemans. Tyrolichus casei is structurally similar to T. putrescentiae, which makes distinguishing between them difficult. The differences occur in the lengths of some of the idiosomal setae, body size, and solenidia shape. Tyrolichus casei has a large, rounded body with small legs (Figure 5a; Hughes, 1976). Figure 5a shows a dorsal view of the mite. The length of the idiosoma is approximately $500 \mu \mathrm{m}$, which agrees with Hughes (1976), who determined that idiosoma length is $500 \mu \mathrm{m}$ for this species (Hughes, 1976).

Figure 5b shows the setae arrangement that resembled that of T. putrescentiae (Hughes, 1976). Tyrophagus casei can be identified because dorsal setae 1 (d1) is the only set of short setae on the idiosoma, whereas dorsal setae 2, 3, and 4, as well as all other idiosomal setae, are long (Hughes, 1976). Dorsal setae 2 is usually 2 to 3 times longer than dorsal setae 1 (Hughes, 1976). The most important feature used to distinguish T. casei from other mite species is that the anterior lateral setae (la) are 4 to 6 times longer than dorsal setae 1, which is a feature that is unique to T. casei (Figure 5b; Hughes, 1976). Figure 5c displays the setae arrangement at the posterior end of the body. Unlike A. siro, which has 2 pairs of short setae and 2 pairs of long setae, T. casei has 8 pairs of long setae (dorsal 3 and 4, posterior lateral, internal sacral, external sacral, and postanal 1, 2, and 3) that extend past the posterior to form a fan-like train (Hughes 1976).

The solenidia of $T$. casei also has a distinct shape that is not shared by other mite species (Figure $5 \mathrm{~d}$ ). It is almost completely cylindrical, with a slight expansion in the middle and no egg-shaped tip (Hughes, 1976). It arises at an angle of approximately $45^{\circ}$ from the leg, beginning at a depression in the tarsus that is shared by the famulus (Hughes, 1976).

The final feature used to distinguish T. casei from other mite species is the supracoxal seta. Figure 6 displays its extended point, expanded base, and distinctive lateral projections (Hughes, 1976).

Acarus siro and T. casei are both found in temperate regions of Europe and North America (Solomon, 1962). They infest such foods as cereal, wheat, flour, fruit, and cheese (Hughes, 1976). Optimal growing conditions are 18 to $25^{\circ} \mathrm{C}$ and 80 to $85 \%$ relative humidity for $A$. siro and $23^{\circ} \mathrm{C}$ and $87 \%$ relative humidity for T. casei. At these conditions, the life cycles of $A$. siro and $T$. casei last 9 to $11 \mathrm{~d}$ and 15 to $18 \mathrm{~d}$, respectively, with reproduction unable to occur below a relative humidity of $60 \%$ (Solomon, 1962; Cunnington, 1965). We were successful at culturing them on a local Parmesan cheese and rye flour at $10^{\circ} \mathrm{C}$ and $80 \%$ relative humidity. Understanding optimal growth conditions and common foods the mites inhabit will benefit producers of these cheeses and will help to prevent or remove infestation on cheeses where these species are not desired. Although these species are purposely inoculated on cheese to produce the European specialty cheeses discussed in this study, they are common food pests that result in cheese spoilage and cheese losses (Peace, 1983). Prevention of infestation has proved to be difficult. Film or wax coatings or low temperature and low relative humidity $\left(3^{\circ} \mathrm{C}\right.$ and $55 \%$, respectively) are effective but are not suitable for rind or surface ripened cheese (Peace, 1983). Good sanitation with cleaning of culturing rooms or ozone is an effective prevention technique.

Identifying the mite species will help us determine what effect they have on cheese flavor. Similar cheese ripening conditions produce 2 very different cheeses, which may be attributed to the effect that each mite species has on its respective cheese. Identifying each species becomes very important for this reason.

\section{CONCLUSIONS}

Only a small number of distinctive morphological features can be used to distinguish between mite species. The features of greatest importance in this study 
were idiosoma length, shape of body and legs, idiosomal setae, solenidia shape, and anus and genital placement (Hughes, 1976). Further literature review on mite ecology and habitat provided clues as to which species were most likely to infest cheese in France and Germany. The number of possible mites was narrowed down to 10 species. Once the mites were viewed through cryoSEM, accurate identification was relatively easy. The Mimolette cheese from France was infested with A. siro. The Milbenkase from Germany was infested with $T$. casei. With these findings, further research can be initiated on the 2 cheese varieties to provide insight on the physical, chemical, and microbial changes that occur on the surface of cheese as a result of resident mites during the ripening process. It will also be possible to determine whether different mite species cause different changes to cheese or whether all mites have a similar effect on the cheese they infest. Cryogenic SEM was a successful method for viewing the mites; however, preserving all idiosomal setae during cryogenic preparation proved to be a challenge. Further work needs to refine this method and ensure preservation of all defining mite features.

\section{REFERENCES}

Cunnington, A. M. 1965. Physical limits for the complete development of the grain mite, Acarus siro L. (Acarina, Acaridae), in relation to its world distribution. J. Appl. Ecol. 2:295-306.

Gorham, J. R. 1987. Insect and Mite Pests in Food: An Illustrated Key. Agriculture Handbook no. 655. USDA, Washington, DC.

Hughes, A. M. 1976. The Mites of Stored Food and Houses. University of London and Ministry of Agriculture, Fisheries and Food, London, UK.

Krantz, G. W. 1978. A Manual of Acarology. 2nd ed. Oregon State University Book Stores Inc, Corvallis, OR.

Kumar, P. L., B. Fenton, G. H. Duncan, A. T. Jones, P. Sreenivasulu, and D. R. V. Reddy. 2001. Assessment of variation in Aceria cajani using analysis of rDNA ITS regions and scanning electron microscopy: Implications for the variability observed in host plant resistance to pigeonpea sterility mosaic disease. Ann. Appl. Biol. 139:61-73.

Ochoa, R., J. S. Pettis, E. Erbe, and W. P. Wergin. 2005. Observations on the honey bee tracheal mite Acarapis woodi (Acari: Tarsonemidae) using low-temperature scanning electron microscopy. Exp. Appl. Acarol. 35:239-249.

Peace, D. M. 1983. Reproductive success of the mite Acarus siro L. on stored cheddar cheese of different ages. J. Stored Prod. Res. 19:97-104

Sargent, J. A. 1986. Cryo-preservation for scanning electron microscopy avoids artefacts induced by conventional methods of specimen preparation. Tissue Cell 18:305-311.

Solomon, M. E. 1962. Ecology of the flour mite, Acarus siro L. (=Tyroglyphus farina DeG.). Proc. Assoc. Appl. Biologists 50:178-184. 